\title{
Emotional Intelligence among Hearing Impaired Children
}

\author{
L. Pujar* and S. Patil \\ Department of Human Development and Family Studies, College of Community Science, \\ University of Agricultural Sciences, Dharwad - 580005, Karnataka, India
}

*Corresponding author

\section{A B S T R A C T}

Keywords

Emotional intelligence, hearing impaired children.

Article Info

Accepted:

20 August 2019 Available Online: 10 September 2019
Emotional intelligence is knowing and managing of personal emotions, sympathizing with others and manipulation of communications in order to be satisfied with them. Thus the study was conducted with an objective to assess the emotional intelligence and factors influencing emotional intelligence of hearing impaired children. Sample consisted of 84 school children selected from $8^{\text {th }}, 9^{\text {th }}$, and $10^{\text {th }}$ standard from residential deaf and dumb schools of Dharwad, Sirsi and Belagavi district during the year 201819. Bar-On emotional intelligence (youth version) and socio-economic (SES) scale were used for the study. Modified chi-square, t-test and ANOVA were used to analyze the data. The results of the present study revealed that, majority $(78.6 \%)$ of hearing impaired children had low and 21.40 per cent had moderate level of emotional intelligence. There was a significant influence of age, ordinal position and socio-economic status on emotional intelligence of hearing impaired children. However there was no significant difference between boys and girls regard to emotional intelligence.

\section{Introduction}

Disability of a person may be permanent or for some period of time and becomes more pertinent when it refers to a special group of population where individual suffers from long-term functional loss either by birth or due to certain other happenings in life. Effects of deafness on children always have social and emotional reflections and it is a stressful experience for parents. Since deaf or hard of hearing person often retard verbal communication with other members of family, could stay in retreat and have not desirable social growth (Hintermair, 2006). In India, 63 million people $(6.30 \%)$ suffer from significant auditory loss. Four in every 1000 children suffer from severe to profound 
hearing loss and also every year over 100,000 babies are born with hearing deficiency. The estimated prevalence of adult-onset deafness in India was found to be 7.60 per cent and childhood onset deafness to be two per cent (Varshney, 2016).

Disability of a person may be permanent or for some period of time and becomes more pertinent when it refers to a special group of population where individual suffers from long-term functional loss either by birth or due to certain other happenings in life. Effects of deafness on children always have social and emotional reflections and it is a stressful experience for parents. Since deaf or hard of hearing person often retard verbal communication with other members of family, could stay in retreat and have not desirable social growth (Hintermair, 2006). In India, 63 million people $(6.30 \%)$ suffer from significant auditory loss. Four in every 1000 children suffer from severe to profound hearing loss and also every year over 100,000 babies are born with hearing deficiency. The estimated prevalence of adult-onset deafness in India was found to be 7.60 per cent and childhood onset deafness to be two per cent (Varshney, 2016).

The effects of hearing loss are not easy to identify and it may vary from general to specific difficulties like language, social, emotional and educational problems. Based on Goleman's theory (1995) emotional intelligence includes knowing and managing of personal emotions, sympathizing with others and manipulation of communications in order to be satisfied with them. Emotional intelligence considered as a general structure that could be the cause of the success of persons in various aspects of life. Goleman believed that persons who has higher emotional intelligence, has more ability in acquiring information and their life is more meaningful.
The emotional intelligence is a good predictor of the person's success in his practical life rather than the whole intelligence which is only a good predictor for the individual's academic success. The people who are highly emotional intelligent are too close to achieve success in their life. The emotional intelligence helps in constructing the individual's personality to be more successful and enjoyable (Al-Hadidi, 2013). Bar-on believed that emotional intelligence is a collection of abilities and skills that mobilizes person for consistency with environment and success. Children with hearing problem have a high risk for behavioural problems, emotional distress and have lower academic achievement compared to typical childhood. In addition, they tend to have low emotional intelligence because of inability to speak or express his or her emotions to their parents and others.

Accordingly, the objective of the study was to assess the emotional intelligence and to know the influence of selected factors on emotional intelligence of hearing impaired children studying in residential deaf and dumb schools.

\section{Materials and Methods}

The target populations of the study comprised of hearing impaired children and were selected from deaf and dumb schools of Sirsi, Belagavi and Dharwad areas of Karnataka, India. Sample comprised of 84 hearing impaired children both boys and girls in the age range of 13 to 17 years, who were studying in $8^{\text {th }}, 9^{\text {th }}$ and $10^{\text {th }}$ standards.

A correlation research design was used to know the relationship and association of emotional intelligence with selected variables. Block education office and principle of respective schools were contacted and permission was taken to carry out the research work. A class wise list of hearing impaired children studying in $8^{\text {th }}, 9^{\text {th }}$ and $10^{\text {th }}$ was made 
and respondents were explained all questions in sign language with the help of class teachers. The structured interview schedule was used to collect personal information such as name, age, gender, education, composition of family, type of family and ordinal position of the child.

The socio-economic status of the family was assessed by using SES scale developed by Aggarwal et al., (2005). Bar-On Emotional quotient inventory- youth version developed by Bar-On and Parker (2000) was used to assess the emotional intelligence.

It is a self-report rating scale designed to measure emotional intelligence of individuals aged between 7 to 18 years. The scale consists of 60 items with four point likert-style from "very seldom true of me", to "very often true of me". Scale has six sub scales namely, intrapersonal, interpersonal, adaptability, stress management, general mood and total emotional intelligence.

Descriptive and inferential statistics such as chi-square, t-test and one-way ANOVA were employed to know the emotional intelligence of hearing impaired children and associated factors.

\section{Results and Discussion}

Table 1 showed the emotional intelligence of hearing impaired children by degree of hearing loss where 38.90 per cent children had low emotional intelligence and 36.40 per cent had moderate level of emotional intelligence and none of them belonged to low level of emotional intelligence among severe category.

Among profound category it was found that 63.60 per cent had moderate and 61.10 per cent had low emotional intelligence with the mean score of $83.43 \pm 10.74$.
There was no significant difference between severe and profound group of hearing impaired children on their level of emotional intelligence. The reason could be that both severe and profound group of hearing impaired children belonged to 70 to more than $90 \mathrm{~dB}$ range of hearing loss which hindering their communication, inter and intrapersonal relationship with their peers might lowered their emotional intelligence.

The figure 1 indicated the percentage distribution of dimension wise emotional intelligence of hearing impaired children. Majority of hearing impaired children were low on interpersonal (53.57\%), stress management $(51.19 \%)$, adaptability $(83.33 \%)$ and moderate intrapersonal (78.57\%) dimensions of emotional intelligence.

An examination of Table 2 the association of emotional intelligence of hearing impaired children by age showed that 65.50 per cent of children ranged from 13- 14 years, 15- 16 years $(90.0 \%)$ and $17-18$ years $(77.30 \%)$ fell under low level of emotional intelligence.

It was found that there was a significant association $\left(\chi^{2}=5.94\right)$ between age and emotional intelligence of hearing impaired children but there was no significant difference found between age groups. Bar-On (2006) assert that difference in the emotional intelligence by age is small in magnitude, however, his notion supports that as one becomes older, one becomes more socially and emotionally intelligence.

The findings are consistent with study done by Uma and Uma (2005) and Nasir and Iqbal (2011) who found significant association between age and emotional intelligence. Tables 3 indicated the association of emotional intelligence of hearing impaired children by gender. 
The results found that majority of male $(79.50 \%)$ and female $(77.50 \%)$ had low level of emotional intelligence. However there was no significant association and difference found between male and female $(\mathrm{t}=0.98)$ hearing impaired children. The reason could be that both boys and girls are staying in residential deaf and dumb schools and equally availed boarding, lodging and educational facilities from $8^{\text {th }}$ std to $10^{\text {th }}$ standard irrespective of gender. The findings are consistent with Yuan et al., (2011) and Yasin (2012) who stated that no gender differences on level of emotional intelligence.

Table 4 indicated the association of emotional intelligence of hearing impaired children by ordinal position. Where all first $(64.30 \%)$, second $(77.40 \%)$ and later born $(96.0 \%)$ were in low level of emotional intelligence. It was found that there was significant association $\left(\chi^{2}=7.92\right)$ and difference found with ordinal position where first born had higher mean score $(86.92 \pm 12.06)$ than the second and later born.

The reason might be children with different birth-order positions may have different opportunities, care and attention that maight have influenced. The study conducted by Vijayalakshmi et al., (2008), Kesavan (2009) and Enny (2013) also highlighted no significant difference between first and later born adolescent in their emotional intelligence.

Table 5 shows the influence of emotional intelligence of hearing impaired children by socioeconomic status (SES). Children from poor as well as middle SES fell under the low (76.60\% and $81.10 \%$ respectively) level of emotional intelligence.

Mean comparison showed children from middle socio-economic status had better emotional intelligence than their counterpart. Chi square analysis revealed there was no significant association between SES and emotional intelligence. There was significant difference found between the two groups of socioeconomic status. The reason could be that parents with better socio-economic status can provide better and conducive family environment for the children emotional growth. The similar to the study Khan and Dar (2013) reported, high SES students were significantly emotionally intelligent than low SES students.

Correlation co-efficient matrix between emotional intelligence and personal factors among hearing impaired children are presented in Table 6.

Ordinal position was significantly negatively correlated with emotional intelligence where as SES was significantly positively correlated with emotional intelligence of hearing impaired children. It indicated that the hearing impaired children who were first born and had better socio-economic status had better emotional intelligence.

The present study focused on emotional intelligence of hearing impaired children and factors influencing emotional intelligence. Most of the hearing impaired children fell under low (78.6\%) level of emotional intelligence and were low on interpersonal, stress management, adaptability and moderate on intrapersonal dimensions of emotional intelligence. There was significant effect of age, ordinal position and socio-economic status on emotional intelligence of hearing impaired children. This calls for educational program for children, teachers and parents to maximize the emotional intelligence of hearing impaired children. Intervention is also required to prevent the negative outcomes and enhance emotional intelligence of children. 
Table.1Percentage distribution of emotional intelligence of hearing impaired children by hearing loss.

$\mathrm{N}=84$

\begin{tabular}{|c|c|c|c|c|c|c|}
\hline \multirow{2}{*}{$\begin{array}{l}\text { Hearing } \\
\text { loss }\end{array}$} & \multicolumn{3}{|c|}{ Levels of emotional intelligence } & \multirow[t]{2}{*}{$\chi^{2}$} & \multirow{2}{*}{$\begin{array}{l}\text { Mean } \\
\text { (SD) }\end{array}$} & \multirow[t]{2}{*}{ t-test } \\
\hline & Low & Moderate & Total & & & \\
\hline Severe & $24(38.9)$ & $7(36.4)$ & $31(100)$ & \multirow[t]{3}{*}{$0.039^{N S}$} & $82.35 \pm 10.74$ & \multirow{3}{*}{$0.44^{\mathrm{NS}}$} \\
\hline Profound & $42(61.1)$ & $11(63.6)$ & $53(100)$ & & $83.43 \pm 10.74$ & \\
\hline Total & $66(78.6)$ & $18(21.4)$ & $84(100)$ & & & \\
\hline
\end{tabular}

Figure in parenthesis indicates percentages, NS-Non Significant

Table.2 Association of emotional intelligence of hearing impaired children by age.

\begin{tabular}{|c|c|c|c|c|c|c|}
\hline \multirow[t]{2}{*}{ Age } & \multicolumn{3}{|c|}{ Levels of emotional intelligence } & \multirow[t]{2}{*}{$\chi^{2}$} & \multirow[t]{2}{*}{ Mean \pm SD } & \multirow[t]{2}{*}{$\mathbf{F}$} \\
\hline & Low & Moderate & Total & & & \\
\hline $13-14$ & $19(65.6)$ & $10(34.5)$ & $29(100)$ & \multirow[t]{3}{*}{$5.94 *$} & $83.48 \pm 8.03$ & \multirow[t]{3}{*}{ 1.29* } \\
\hline 15- 16 & $30(90.0)$ & $3(9.1)$ & $33(100)$ & & $80.93 \pm 11.38$ & \\
\hline 17-18 & $17(77.3)$ & $5(22.7)$ & $22(100)$ & & $83.03 \pm 10.63$ & \\
\hline
\end{tabular}

Figure in parenthesis indicates percentages, NS-Non Significant, *- Significant

Tables.3 Association of emotional intelligence of hearing impaired children by gender.

\begin{tabular}{|l|l|l|l|l|l|l|}
\hline \multirow{2}{*}{ Gender } & \multicolumn{3}{|l|}{ Levels of emotional intelligence } & \multirow{2}{*}{$\chi^{2}$} & Mean \pm SD & \multirow{2}{*}{ t-value } \\
\cline { 2 - 4 } & Low & Moderate & Total & & & \\
\cline { 1 - 6 } Male & $35(79.5)$ & $9(20.5)$ & $44(100)$ & $0.05^{\mathrm{NS}}$ & $84.13 \pm 10.0$ & $0.98^{\mathrm{NS}}$ \\
\hline Female & $31(77.5)$ & $9(22.5)$ & $40(100)$ & & $81.82 \pm 11.41$ & \\
\hline
\end{tabular}

Figure in parenthesis indicates percentages, NS-Non Significant

Table.4 Association of emotional intelligence of hearing impaired children by ordinal position.

\begin{tabular}{|c|c|c|c|c|c|c|}
\hline \multirow[t]{2}{*}{ Ordinal position } & \multicolumn{2}{|c|}{$\begin{array}{l}\text { Levels of } \\
\text { intelligence }\end{array}$} & emotional & \multirow[t]{2}{*}{$\chi^{2}$} & \multirow[t]{2}{*}{ Mean \pm SD } & \multirow[t]{2}{*}{$\mathbf{F}$} \\
\hline & Low & $\begin{array}{l}\text { Moderat } \\
\text { e }\end{array}$ & Total & & & \\
\hline First born & $18(64.3)$ & $10(35.7)$ & $28(100)$ & \multirow[t]{3}{*}{$7.92 *$} & $86.92 \pm 12.06$ & \multirow[t]{3}{*}{$8.18^{*}$} \\
\hline Second born & $24(77.4)$ & $7(22.6)$ & $31(100)$ & & $84.80 \pm 9.33$ & \\
\hline Later born & $24(96.0)$ & $1(4.0)$ & $25(100)$ & & $76.48 \pm 7.50$ & \\
\hline
\end{tabular}

Figure in parenthesis indicates percentages, NS-Non Significant, *- Significant 
Table.5 Association of emotional intelligence of hearing impaired children by socio- economic status (SES).

\begin{tabular}{|c|c|c|c|c|c|c|}
\hline \multirow[t]{2}{*}{ SES } & \multicolumn{3}{|c|}{$\begin{array}{lll}\text { Levels of } & \text { emotional } \\
\text { intelligence } & & \end{array}$} & \multirow[t]{2}{*}{$\chi^{2}$} & \multirow[t]{2}{*}{ Mean \pm SD } & \multirow[t]{2}{*}{$\begin{array}{l}\text { t- } \\
\text { value }\end{array}$} \\
\hline & Low & Moderate & Total & & & \\
\hline \multirow[t]{2}{*}{ Poor } & \multirow[t]{2}{*}{$36(76.6)$} & \multirow[t]{2}{*}{$11(23.4)$} & \multirow[t]{2}{*}{47 (100) } & \multirow[t]{3}{*}{$0.25^{\mathrm{NS}}$} & $86.0 \pm 9.85$ & \multirow[t]{3}{*}{$2.99^{*}$} \\
\hline & & & & & $72.27 \pm 10.65$ & \\
\hline Middle & $30(81.1)$ & $7(18.91)$ & 37 (100) & & & \\
\hline
\end{tabular}

$\mathrm{N}=84$

Figure in parenthesis indicates percentages, NS-Non Significant, *- Significant

Table.6 Correlation co-efficient matrix between emotional intelligence and personal factors of hearing impaired children

\begin{tabular}{|l|l|l|l|}
\hline Particulars & Age & $\begin{array}{l}\text { Ordinal } \\
\text { position }\end{array}$ & $\begin{array}{l}\text { Socio- economic } \\
\text { Status }\end{array}$ \\
\hline Emotional intelligence & $0.09^{\mathrm{NS}}$ & $-0.38^{*}$ & $0.42^{*}$ \\
\hline
\end{tabular}

*significant at 0.05 level ${ }^{\mathrm{NS}}$-Non-significant

Fig.1 Percentage distribution of hearing impaired children by dimensions if emotional intelligence.

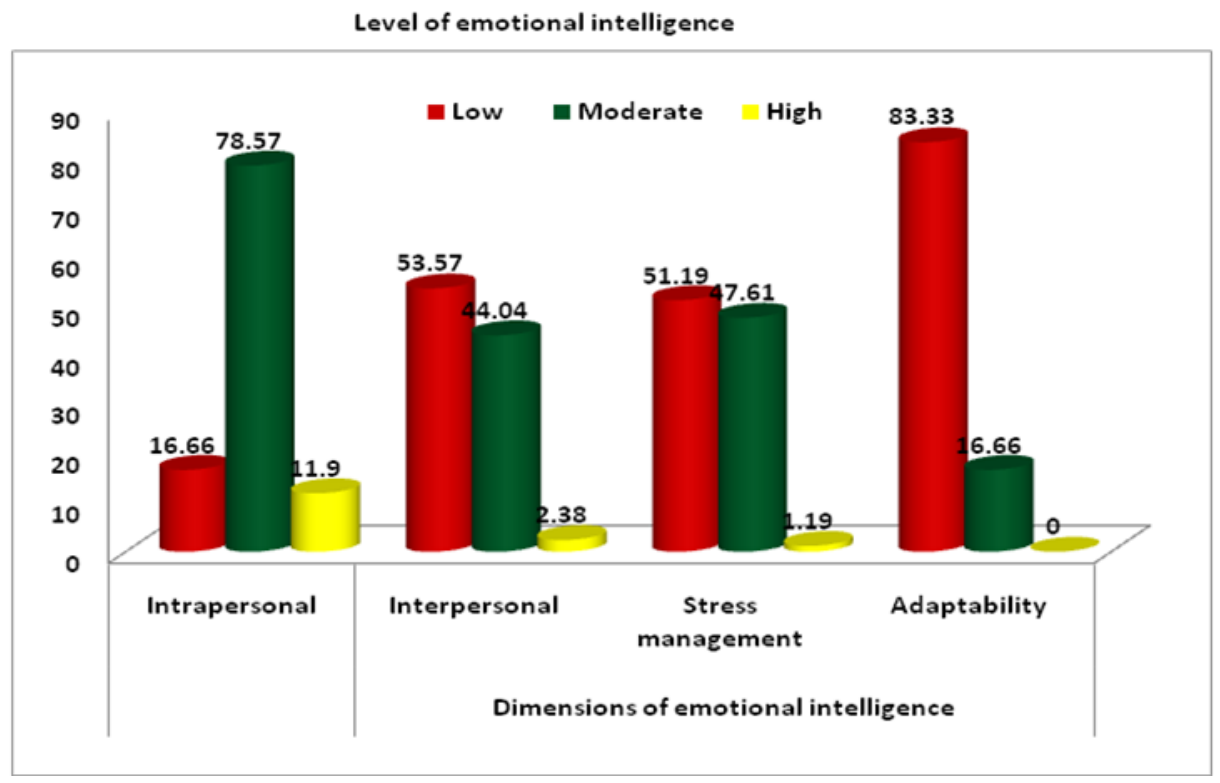




\section{References}

Agarwal, O. P., Bhasin, S. K., Sharma, A. K., Chhabra, P., Aggarwal, K. and Rajoura, O. P., 2005, A new instrument (scale) for measuring the socio-economic status of a family : preliminary study. Ind. J. Comm. Med., 34(4): 111-114.

Al-Hadidi, M., 2013, Introduction in the people with special needs education. Dar Fikr books for publishing and distribution.

Bar-On, R. and Parker, J. D. A., 2000, Bar-On Emotional Quotient Inventory: Youth Version. Technical Manual. MultiHealth Systems. Inc., North Tonawanda, NY. pp. 3 - 30 .

Bar-On, R., 2006, The Bar-On Emotional Quotient Inventory Manual, Toronto, 5 -10 .

Enny, W. E., 2013, Emotional Intelligence, general mental ability, and academic achievement of adolescents. Unpublished M.A. Dissertation, University of Agricultural Sciences, Dharwad.

Goleman D., 1995, Emotional Intelligence: Why it can matter more than IQ. Bantam books. New York.

Hintermair M. 2006. Parental Resources, Parental Stress, and Socio emotional Development of Deaf and Hard of Hearing Children. J. Deaf Studies and
Deaf Education, 11(4), 493-513. doi: 10.1093/deafed/enl005

Kesavan, P. S., 2009, A study on emotional intelligence, multiple intelligence, socio-economic status and academic achievement of higher secondary students. PhD. Thesis Periyar Univ. Salem (India).

Nasir, M. and Iqbal, S., 2011, Relationship of demographic factors with emotional intelligence of University students. New Horti. Sci. Techn., 1(1):17-21.

Uma, M. and Devi, R., 2005, Relationship between the dimensions of emotional intelligence of adolescents and selected personal variables. Indian. Psychol. Rev., 69(1):20-25

Varshney, S., 2016, Deafness in India. Indian J. Otol., 22(2): 73-76.

Vijayalakshmi, V., Bhattacharyya, S., Bhartia, A. and Muthuvel, R., 2008, Emotional intelligence and social reticence of post-graduate female students. $J$. Indian Acad. Appl, Psychol., 34 (1):93100

Yasin, M.H. M., 2012, Emotional intelligence among deaf and hard of hearing children. The Soc. Sci., 7(5): 679-682.

Yuan, W., Fang. and Xiaobo L., 2011, Research on the Emotional Intelligence of Deaf Students. China J health Psy., 1: 1-9. Science of Education Institute of Hunan Normal University, Changsha 410081, P.R.China.

\section{How to cite this article:}

Pujar L. and Patil S. 2019. Emotional Intelligence among Hearing Impaired Children. Int.J.Curr.Microbiol.App.Sci. 8(09): 1818-1824. doi: https://doi.org/10.20546/ijcmas.2019.809.210 